\title{
A relação prazer-sofrimento no contexto de trabalho de startups, à luz da psicodinâmica do trabalho
}

\author{
The relation pleasure-suffering \\ in the labour context of startups, in \\ the light of the psychodynamics of work
}

\author{
PALOMA ALVES SARAIVA TELES (D) \\ ANA CRISTINA BATISTA DOS SANTOS D \\ BRENNO BUARQUE D \\ ANA RAQUEL SILVA ROCHA D
}

\section{RESUMO}

A pesquisa buscou compreender como se caracteriza a relação prazer-sofrimento, no contexto de trabalho em startups, à luz da Psicodinâmica do Trabalho (PDT). O referencial teórico foi composto pela conceituação de startups e seu desenvolvimento no mundo do trabalho, seguida da apresentação da lente teórica, a PDT, e suas macrodimensões. O método da pesquisa foi de cunho qualitativo, com coleta de dados por meio de cinco entrevistas semiestruturadas, com trabalhadores de três startups, as quais foram transcritas, categorizadas e analisadas a partir da técnica de Análise dos Núcleos de Sentido (ANS). Diante dos achados do estudo, conclui-se que o contexto laboral das startups possui, de forma mais representativa, vivências de prazer, pois o sofrimento não foi objetivamente identificado, mas sim diversas situações que podem promover sua posterior emergência, bem como aspectos limitantes que se colocam como barreiras ao prazer. $\mathrm{O}$ estudo contribui com uma incipiente e relevante combinação 
de construtos, proporcionando subsídios para diálogos teóricos futuros, além de contribuições práticas para os gestores das startups compreenderem seu contexto laboral e traçarem estratégias para a melhoria da relação homem-trabalho, estimulando seu potencial inovativo.

Palavras-chave: Startups. Psicodinâmica do trabalho. Prazer-sofrimento.

\section{Abstract}

The research has the objective to understand how the pleasure-suffering relationship is characterized, in the context of work in startups, in the light of the Psychodynamics of Work. The theoretical framework was composed by the conceptualization of startups and their development in the world of work, followed by the presentation of the theoretical lens, the Psychodynamics of Work, and their macro dimensions. The research methodology was qualitative, with data collection through five semi-structured interviews, with workers from three startups, which were transcribed, categorized and analyzed using the Core Analysis of Sense technique. The findings of the study concluded that the work context of startups has, in a more representative way, experiences of pleasure, as suffering was not objectively identified, but rather several situations that can promote their subsequent emergence, as well as aspects limiting factors that pose barriers to pleasure. The study contributes with an incipient and relevant combination of constructs, providing subsidies for theoretical dialogues, as well as practical contributions for startup managers to understand their work context and outline strategies to improve the man-work relationship and its innovative potential. Keywords: Startups. Psychodynamics of work. Pleasure-suffering.

\section{INTRODUÇÃo}

A inovação é uma temática bastante abordada na contemporaneidade apresentando muita relevância na sociedade e nas organizações. No contexto organizacional, a inovação surge através do alinhamento entre o conhecimento e a colaboração, possibilitando constantes melhorias nos produtos e processos, que contribuem para o alcance de maiores resultados nas organizações (AGGARWAL; WU, 2018). Assim, o estudo das características e peculiaridades dos 
ambientes inovativos, bem como os aspectos socioculturais desses ambientes são de grande relevância para as organizações.

Nesse contexto, segundo Gitahy (2016), as startups começaram a surgir nos EUA no final da década de 1990, apresentando um modelo de negócio com a capacidade de implementar inovações no mundo do trabalho. Essas empresas chegaram ao Brasil nos anos 2000 e ganharam potencialidade a partir de 2010, apresentando grande potencial de inovação para as organizações (GITAHY, 2016). Mendes (2007) afirma que a reorganização dos processos que começou a ocorrer nas organizações a partir de 1990, acarretou muitas transformações nas empresas que passaram a gerar novos modos de respostas dos trabalhadores, em relação ao trabalho.

Neste trabalho, abordam-se as dinâmicas sociais e os aspectos laborais das startups, objetivando fortalecer a temática de estudos contemporâneos em inovação tecnológica e estudos organizacionais, além de promover conhecimento acerca do assunto possibilitando que as empresas atinjam maior desempenho organizacional (ISIDRO-FILHO; GUIMARÃES, 2010). De acordo com Ries (2012), o conceito de startup não apresenta detalhes sobre qual a atividade, campo de atuação ou tamanho que a empresa deve seguir, ele define como uma organização formada por pessoas que têm como objetivo elaborar produtos e serviços novos em uma situação de extremo desconhecimento.

A partir dessa compreensão, é interessante ressaltar que o surgimento das startups se relaciona com as mudanças que vêm ocorrendo no mundo do trabalho como um todo (GROHMANN, 2018). De acordo com Marcelino (2011), um termo muito utilizado nesse contexto é a flexibilização, o qual se refere à diminuição de direitos, por exemplo, dos trabalhadores e ocorre com a incorporação de novas tecnologias ocasionando modificações nos processos produtivos e de comunicação, tornando-os mais flexíveis.

Segundo Machado, Blattmann e Teixeira (2018), as pesquisas realizadas sobre startups tratam de assuntos direcionados para tecnologia, inovação, gestão e negócios, podendo destacar os estudos de: Benson e Ziedones (2009); Kohler (2016); Wallin, Still e Henttonen (2016). Esses temas estão relacionados com a Administração e geram maior conhecimento sobre esse modelo de organização que vem surgindo. 
O modelo supramencionado apresenta novas formas de gestão e diferentes formas de trabalho dentro das organizações. Sendo assim, o trabalhador que está dentro desse contexto pode ser afetado diretamente e isso pode impactar nas suas relações de trabalho, no seu desempenho e na sua produtividade. A partir disso, é possível observar que existe uma necessidade de compreender o trabalhador que está inserido dentro do ambiente de startups, visto que ele faz parte do processo de construção e desenvolvimento desse tipo novo de negócio.

Segundo Oliveira (2017), poucas pesquisas têm se voltado para o estudo dos aspectos subjetivos e intersubjetivos de trabalhadores de startups, à luz da Psicodinâmica do Trabalho, tratando sobre a relação prazer-sofrimento, explorando as atividades e relações de trabalho. $\mathrm{O}$ autor identifica alguns dos elementos que geram prazer ou sofrimento e as estratégias utilizadas pelos trabalhadores para lidar com esses sentimentos em sua área de atuação, além de ressaltar a necessidade de se realizar mais pesquisas para entender esta temática no contexto do atual mundo do trabalho, que tem sofrido mudanças e tem gerado diversas consequências para o trabalhador, em relação ao sentido que atribui ao trabalho, bem como as relações construídas e as suas motivações.

A Psicodinâmica do Trabalho (PDT) surgiu com a necessidade de compreender a relação entre o trabalho e saúde mental, e como os trabalhadores encaram o sofrimento (GERNET, 2016), pois, o modo como o trabalho é organizado produz ações que refletem no homem, ocasionando sofrimento e surgimento de doenças psicológicas (DEJOURS, 1992). A PDT, na corrente dejouriana, estuda as dimensões de contexto do trabalho, que são a organização do trabalho, as condições de trabalho e as relações de trabalho; e as dimensões de conteúdo, que envolvem carga psíquica, vivências de prazer-sofrimento, estratégias de enfrentamento ou defensivas e reconhecimento (DEJOURS; ABDOUCHELI; JAYET, 1994; MENDES, 2007).

Diante da compreensão de que as dimensões de conteúdo se desenvolvem a partir das dimensões de contexto, contemplando vivências e dinâmicas que conduzem o sujeito ao prazer e ao sofrimento, além de favorecerem, respectivamente, estados de saúde e adoecimento, este artigo elegeu o construto prazer-sofrimento para o estudo, 
diante da dinamicidade que circunda as definições e características socializadas sobre startups. A questão de pesquisa que orientou o estudo foi: como se caracteriza a relação prazer-sofrimento, no contexto de trabalho das startups, à luz da psicodinâmica do trabalho?

O objetivo geral do estudo foi compreender como se caracteriza a relação prazer-sofrimento, no contexto de trabalho em startups, à luz da psicodinâmica do trabalho. Foram selecionados cinco trabalhadores de startups para participar de entrevistas individuais e responder esta pesquisa.

A estrutura deste artigo é distribuída em cinco partes, sendo elas: esta introdução, seguida com a revisão de literatura, que aborda ambientes inovativos, em específico startups, e as macrodimensões da Psicodinâmica do Trabalho. A seção seguinte descreve a metodologia utilizada na pesquisa. A quarta seção caracteriza e analisa os dados da pesquisa de campo e, por fim, segue-se com as considerações finais, onde são apresentadas as conclusões mais relevantes identificadas durante a pesquisa.

\section{STARTUPS}

As startups são empresas que possuem rápida capacidade de escalonamento e inserção nos mercados, além de sua dinâmica dentro da gestão empresarial possuir características peculiares quando comparadas às empresas tradicionais (GITAHY, 2016). Ries (2012) conceitua que as startups são empresas que estão em sua fase inicial, que tem como objetivo criar produtos ou serviços inovadores, em um ambiente de incerteza extrema.

Segundo Miranda, Santos Júnior e Dias (2016) o ambiente de trabalho em uma startup, principalmente as que estão nas fases iniciais de desenvolvimento, possui certo grau de incerteza e risco. Por serem empresas que passam por um crescimento acelerado, essas organizações estão constantemente modificando seus processos e suas formas de trabalho. As startups se utilizam de modelos de gestão ágeis, que aceleram o processo de aprendizado e desenvolvimento de seus colaboradores e dos processos de negócio (MIRANDA; SANTOS JÚNIOR; DIAS, 2016).

Ries (2012) afirma que a inovação é uma característica presente nas startups, seja por meio de uma descoberta tecnológica, modifi- 
cações em processos tradicionais ou criação de oportunidades que facilitem o acesso a produtos e serviços. É importante também ressaltar que são criadas em ambientes de incerteza que geram constantes mudanças no processo de elaboração e entrega do produto, pois são modelos de negócios inovadores que ainda não foram executados. Sendo assim, as estratégias e ferramentas utilizadas nas empresas tradicionais são difíceis de ser aplicadas nesses novos modelos, visto que não foram elaboradas para cenários instáveis (RIES, 2012).

Segundo Van Gelderen, Thurik e Bosma (2005), o processo de criação de uma startup é fundamental para determinar seu sucesso ou fracasso e um dos fatores determinantes para isso é o comprometimento do time com o negócio. A formação do time inicial e os relacionamentos que estes profissionais possuem também são fatores importantes para o sucesso das startups (DIÁNEZ-GONZÁLEZ; CAMELO-ORDAZ, 2016; HUYNH et al., 2017; MCGRATH; MEDLIN; O'TOOLE, 2019), pois se refletem fortemente na capacidade de captação de recursos para o desenvolvimento inicial do projeto e nas capacidades de empreendedorismo e de gestão da equipe.

As startups são classificadas em determinadas etapas de desenvolvimento, de acordo com a maturidade tecnológica de seu produto ou serviço, e com sua capacidade de produção e comercialização (ABSTARTUPS, 2020). Assim, usualmente são classificadas em quatro etapas: i) ideação, onde ocorre a fase de teste da hipótese e validação do negócio; ii) operação, onde a empresa entra em operação, formando e expandindo a sua base de clientes; iii) tração, na qual o negócio irá crescer e escalar; iv) scaleup, que se segue após o crescimento, com foco na captação de investimentos de terceiros e na internacionalização do negócio.

Assim, esta nova dinâmica de crescimento e desenvolvimento dessas empresas implicam em um novo contexto de trabalho e em novas vivências para o trabalhador, à medida que a sua forma de trabalhar e os relacionamentos construídos são fortemente influenciados pelo ambiente em que estão inseridos e pelas demandas advindas dele. Desse modo, surge a necessidade de compreensão dessa nova dinâmica de trabalho e de suas implicações para o mundo do trabalho. 


\section{PSicodinÂMica do trabalHo}

A Psicodinâmica do Trabalho emergiu na França, com Christophe Dejours que, na década de 1980, passou a investigar as psicopatologias do trabalho, buscando compreender as dinâmicas que compõem o contexto laboral e seus processos de subjetivação (ANCHIETA et al., 2011). Para a PDT, o contexto de trabalho é o cenário onde se manifestam os aspectos psicodinâmicos, sendo composto por três dimensões: organização do trabalho, relações sociais de trabalho e condições de trabalho (DEJOURS, 1992).

A organização do trabalho é considerada por Dejours (1992) a principal responsável por benefícios ou danos aos processos psíquicos desenvolvidos pelo trabalhador, pois é constituída por aspectos como a divisão do trabalho, os tipos de atividades, a hierarquia e as formas de comando e de poder.

As relações de trabalho abrangem todos os laços existentes entre os sujeitos no ambiente laboral (DEJOURS, 1992), como interações hierárquicas, interações intra e intergrupos e as interações externas (MENDES; FERREIRA, 2008), envolvendo clientes e fornecedores.

As condições de trabalho, para Dejours (1992), incluem as características do ambiente físico, químico, biológico, as condições de higiene e de segurança do posto de trabalho. Variáveis como tecnologias, matéria-prima, suporte organizacional e práticas de desenvolvimento de pessoal, também têm sido consideradas como componentes da dimensão em questão (MENDES; FERREIRA, 2008).

Dejours, Abdoucheli e Jayet (1994) afirmam que os indivíduos inseridos em um contexto de trabalho reagem de forma diferente às dificuldades oriundas das situações laborais, pois chegam a este trabalho trazendo consigo suas histórias de vida e suas características pessoais que confrontarão as exigências do âmbito profissional. Assim, o trabalho é carregado de sentido e nele os sujeitos buscam equacionar o pensar, agir e sentir (MENDES; FERREIRA, 2008), mas quando inseridos em um contexto de trabalho específico, podem vivenciar prazer e/ou sofrimento, e seus desdobramentos.

Segundo Giongo, Monteiro e Sobrosa (2015), um dos grandes elementos que desperta o prazer dos sujeitos é a atribuição de sentido ao próprio trabalho, clarificando o propósito e a importância do seu saber-fazer tanto para si, quanto para outras pessoas. Outra 
forma de vivenciar o prazer no contexto em questão ocorre quando a organização do trabalho possibilita que os indivíduos se utilizem de sua criatividade e inventividade no cotidiano laboral, sendo um contexto flexível e promotor dos sentimentos de utilidade e de valorização (MERLO; MENDES, 2009).

Cabe salientar que tal valorização não precisa ocorrer apenas através de retribuições materiais, pois, de acordo com Dejours (2013), a retribuição que a maioria dos trabalhadores busca é a simbólica, que se dá pelo reconhecimento, o qual pode ser fornecido como gratidão pelo trabalho realizado; ou pelos julgamentos, seja sobre a utilidade do trabalho, geralmente proferido pelas altas posições hierárquicas, seja pela beleza da contribuição, em termos estéticos, julgamento proferido geralmente pelos pares. No entanto, sendo o reconhecimento um potencial gerador de prazer, sua ausência destrói o sentido subjetivo do trabalho, impedindo a transformação do sofrimento, desfavorecendo a saúde do sujeito a ponto de surgirem patologias (AGUIAR; BATISTA-DOS-SANTOS, 2017).

Para Dejours (1992), o sofrimento no trabalho ocorre no momento em que o sujeito precisa enfrentar situações oriundas de determinadas formas de organização do trabalho sem abertura para o uso da sua inteligência. $\mathrm{O}$ autor aponta que, quando chefes se relacionam com seus subordinados utilizando a pressão para alcance dos resultados, por exemplo, o sofrimento surge nos trabalhadores, podendo levar ao adoecimento psíquico.

Diante disso, as vivências de sofrimento emergem quando existe um bloqueio na relação entre o trabalhador e a organização do trabalho que se apresenta a ele, fato decorrente das divergências entre os desejos de ambas as partes (MENDES, 2007). Nessa circunstância, os sujeitos podem se utilizar de estratégias de defesa, ou de enfrentamento, as quais podem ser individuais ou coletivas, podendo ser manifestadas em diferentes formas: por meio de expressões físicas (choro e riso); atitudes (negação, agressividade, afastamento); ou práticas de distração (religião, atividade física, terapia) (GIONGO; MONTEIRO; SOBROSA, 2015).

No entanto, ao sustentarem uma falsa estabilidade psíquica, tais estratégias podem estar substituindo a transformação do sofrimento por um simples disfarce do mesmo, favorecendo o adoecimento. $\mathrm{O}$ 
adoecimento no trabalho encontra espaço para emergir em situações nas quais o trabalhador não possui os recursos psicológicos necessários para lidar com esse cenário (ANCHIETA et al., 2011).

Segundo Carvalho e Moraes (2011), o crescimento de patologias nos contextos de trabalho pode ter sido apoiado pela crescente flexibilização dos mesmos, diante da aceleração dos processos, aumento das pressões por resultados, além da precarização das relações de trabalho. A conjuntura supramencionada pode ser identificada em organizações contemporâneas, como algumas startups, fato que vincula aos benefícios da flexibilidade fatores como estresse e sobrecarga que, para Nogueira e Freitas (2015), comumente afetam, de forma direta, o modo como o trabalhador reage às pressões do ambiente de trabalho para manter o equilíbrio.

Além disso, outras patologias são facilmente identificáveis na contemporaneidade, como a depressão e a ansiedade (CARVALHO; MORAES, 2011). Logo, o entendimento do processo de adoecimento do trabalhador é fundamental para a identificação dos gatilhos existentes na dinâmica de prazer-sofrimento, viabilizando a intensificação de estratégias promotoras da saúde no contexto de trabalho.

\section{Metodologia}

A abordagem metodológica utilizada no estudo foi qualitativa, a qual permite que o pesquisador fique imerso para analisar e observar significados de forma aprofundada, que não podem ser quantificados e convertidos em variáveis (MINAYO et al., 2003; VIEIRA; RIVERA, 2012). Dejours (1992) afirma que a abordagem qualitativa é a mais adequada para compreender as vivências de prazer e sofrimento, visto que permite analisar a dimensão subjetiva emergente nas falas dos entrevistados.

A tipologia da pesquisa foi exploratório-descritiva. Exploratória por permitir uma maior proximidade com um tema ainda pouco pesquisado e, consequentemente, avançar em aprofundamentos; e descritiva por documentar, analisar e interpretar dados coletados num contexto empírico específico (ANDRADE, 2003).

Quanto aos meios, foi utilizada a técnica de entrevistas individuais em profundidade como forma de coleta dos dados. A entrevista é uma forma de acessar ideias, comportamentos, sentimentos 
e opiniões, e essa técnica tem como objetivo reunir os dados necessários para a pesquisa, a partir da teoria em que está fundamentada (MINAYO, 2004). De acordo com Mendes (2007), nas pesquisas de PDT a fala é valorizada, pois é a partir dela que é possível coletar informações explícitas e implícitas existentes no trabalho.

Foi utilizado um roteiro durante a aplicação das entrevistas, como forma de guiar a conversa. No início da entrevista foi pedido que os entrevistados iniciassem contando a sua trajetória na empresa. Essa pergunta teve como objetivo fazer a evocação do vivido, por meio das memórias sobre suas histórias de trabalho no contexto específico das startups. As demais perguntas foram realizadas sob os tópicos-guia, com o intuito de orientar a condução da entrevista, mas de modo que não impedisse o aprofundamento de aspectos que poderiam ser relevantes para o entendimento do objeto de estudo (GASKELL; BAUER, 2002). As temáticas abordadas foram: organização do trabalho, condições de trabalho, relações de trabalho, dinâmicas de prazer-sofrimento, todos circunstanciados no contexto das startups.

Para determinar o momento de parar as entrevistas foi utilizado o método de saturação empírica que, de acordo com Minayo (2017), não leva em consideração a quantidade de entrevistas, mas a qualidade e a diversidade de insumos, embasados na teoria que fundamenta a pesquisa. Esse processo é realizado até o momento em que os dados não apresentam mais aspectos relevantes para o estudo.

Conforme a metodologia descrita, foram realizadas cinco entrevistas com trabalhadores de três startups, para as quais se utilizaram termos de consentimento e confidencialidade. Essas startups atuam na área de educação, de finanças e gerenciamento de bens e serviços para empresas terceiras. Os sujeitos da pesquisa foram selecionados com base na amostragem por conveniência, e estão descritos no Quadro 1, com o objetivo de apresentar o perfil dos entrevistados, sendo representados por meio dos códigos E1 a E5. 


\section{Quadro 1 - Perfil dos Entrevistados}

\begin{tabular}{|c|c|c|c|c|c|c|}
\hline $\begin{array}{l}\text { CAMPO DA } \\
\text { STARTUP }\end{array}$ & $\begin{array}{l}\text { SUJEI- } \\
\text { TOS }\end{array}$ & $\begin{array}{l}\text { GÊ- } \\
\text { NERO }\end{array}$ & $\begin{array}{l}\text { IDA- } \\
\text { DE }\end{array}$ & $\begin{array}{l}\text { ESCOLARIDA- } \\
\text { DE }\end{array}$ & CARGO & $\begin{array}{l}\text { ESTADO } \\
\text { CIVIL }\end{array}$ \\
\hline FINANÇAS & E1 & $\begin{array}{l}\text { Mas- } \\
\text { culino }\end{array}$ & 21 & $\begin{array}{l}\text { Superior } \\
\text { Incompleto }\end{array}$ & $\begin{array}{l}\text { Estagiário } \\
\text { Financeiro }\end{array}$ & Solteiro \\
\hline $\begin{array}{l}\text { GERENCIA- } \\
\text {-MENTO } \\
\text { DE BENS E } \\
\text { SERVIÇOS }\end{array}$ & E2 & $\begin{array}{l}\text { Mas- } \\
\text { culino }\end{array}$ & 21 & $\begin{array}{l}\text { Superior } \\
\text { Incompleto }\end{array}$ & Estagiário & Solteiro \\
\hline EDUCAÇÃO & E3 & $\begin{array}{l}\text { Mas- } \\
\text { culino }\end{array}$ & 20 & $\begin{array}{l}\text { Superior } \\
\text { Incompleto }\end{array}$ & $\begin{array}{l}\text { Especialista } \\
\text { Educacional }\end{array}$ & Solteiro \\
\hline EDUCAÇÃO & E4 & $\begin{array}{l}\text { Femi- } \\
\text { nino }\end{array}$ & 22 & $\begin{array}{l}\text { Superior } \\
\text { Incompleto }\end{array}$ & $\begin{array}{l}\text { Customer } \\
\text { Success }\end{array}$ & Solteira \\
\hline EDUCAÇÃO & E5 & $\begin{array}{l}\text { Femi- } \\
\text { nino }\end{array}$ & 28 & $\begin{array}{l}\text { Superior Com- } \\
\text { pleto }\end{array}$ & $\begin{array}{l}\text { Analista de } \\
\text { Novas Receitas }\end{array}$ & Solteira \\
\hline
\end{tabular}

O processo de análise de dados foi iniciado na transcrição das entrevistas, em que se realizou uma análise inicial das falas dos entrevistados e em seguida a categorização dos trechos mais relevantes, através da técnica ANS. Essa técnica foi adaptada por Mendes (2007), no âmbito da PDT, a partir da análise temática de conteúdo (BARDIN, 2011). Na ANS, privilegia-se as dimensões semântica, lógica e psicológica do discurso. De acordo com Mendes (2007), a análise dos núcleos de sentido é feita a partir da interpretação das falas dos entrevistados, levando em conta, entre outas coisas, as figuras de linguagem, para caracterizar os significados e formar os temas. A força dos temas é definida por sua representatividade na totalidade dos discursos e sua consistência interna, isto é, a quantidade de excertos de fala que lhes constituem. O software utilizado para realizar a análise foi o Atlas TI.

A proporção entre o número de entrevistas que apresentaram núcleos de sentido ligados ao tema, e o número total de entrevistas é denominado representatividade. A consistência interna é formada pela quantidade de núcleos de sentido que um tema possui em relação a quantidade total dos núcleos de sentido. Sendo assim, os 
temas que apresentaram menor representatividade e núcleos de sentido foram descartados ou agrupados com temas mais fortes como subtemas para auxiliar no momento da explicação dos temas, facilitando a compreensão. O quadro 2 apresenta a análise da representatividade e da consistência interna dos temas.

Quadro 2 - Análise da Representatividade e da Consistência dos Temas Emergentes da Categorização dos Dados

\begin{tabular}{|l|l|l|}
\hline Temas & Representatividade & Consistência interna \\
\hline $\begin{array}{l}\text { Organização do Traba- } \\
\text { lho }\end{array}$ & $5 / 5$ & 37 \\
\hline Flexibilidade & $5 / 5$ & 32 \\
\hline Relações de Trabalho & $5 / 5$ & 33 \\
\hline Condições de Trabalho & $5 / 5$ & 19 \\
\hline Mudanças & $4 / 5$ & 14 \\
\hline Reconhecimento & $5 / 5$ & 12 \\
\hline Estratégia de Defesa & $2 / 5$ & 6 \\
\hline
\end{tabular}

Fonte: elaborado pelos autores.

Com o objetivo de atingir a saturação empírica, que ocorre quando as últimas entrevistas realizadas não abordam informações novas (PIRES, 2008), a pesquisa utiliza a abordagem de Fontanella et al. (2011), através da recorrência dos temas nas entrevistas, conforme quadro 3.

\section{ANÁlise E disCuSSÃo doS RESUltados}

Nesta seção, são analisados e discutidos os dados coletados no campo, provenientes das entrevistas com os trabalhadores de startups, das quais emergiram os seguintes temas: flexibilização; mudanças; organização do trabalho; relações de trabalho; condições de trabalho; reconhecimento e estratégias de defesa. 


\section{Quadro 3 - Recorrência dos temas nas entrevistas}

\begin{tabular}{|c|c|c|c|c|c|c|}
\hline \multirow[b]{2}{*}{ Temas } & \multicolumn{6}{|c|}{ Entrevistas } \\
\hline & E1 & E2 & E3 & E4 & E5 & $\begin{array}{l}\text { Total } \\
\text { de ocorrências }\end{array}$ \\
\hline Organização do Trabalho & $!$ & + & + & + & + & 5 \\
\hline Flexibilidade & $!$ & + & + & + & + & 5 \\
\hline Relações de Trabalho & $!$ & + & + & + & + & 5 \\
\hline Condições de Trabalho & $!$ & + & + & + & + & 5 \\
\hline Mudanças & $!$ & + & + & + & & 4 \\
\hline Reconhecimento & $!$ & + & + & + & + & 5 \\
\hline Estratégia de Defesa & & & $!$ & + & & 2 \\
\hline $\begin{array}{l}\text { Total de novos temas para } \\
\text { cada entrevista }\end{array}$ & 6 & 0 & 1 & 0 & 0 & - \\
\hline
\end{tabular}

! : novo tema; +: recorrências.

Fonte: elaborado pelos autores, baseado em Fontanella et al. (2011).

\subsection{Flexibilização}

O tema flexibilização emergiu na fala dos cinco entrevistados, sendo o terceiro assunto mais recorrente nas entrevistas, envolvendo aspectos como horário de trabalho flexível, rotinas de home office e dress code menos rígido.

Alguns entrevistados pontuaram tal temática através de comparações com empresas tradicionais, evidenciando a predominância da flexibilidade no âmbito das startups: "A flexibilidade, o principal para mim é porque é rápida [...] E é isso, a flexibilidade também é mais tranquilo tal, mesmo que as empresas tradicionais elas tentem, não são do mesmo jeito, entendeu? Ainda são muito fechadas" (E4); "É flexível a depender do time [...] e assim, por mais que não seja super flexível, startup ainda é mais flexível do que no mercado tradicional, você vê diretamente o seu impacto. Eu tive oportunidade de lidar diretamente com o CEO cara, entendeu? E não é que "aí meu Deus, status" não, é porque você tem uma liberdade maior. Você não tá assim, como se tivessem 30 camadas" (E5). 
No entanto, alguns entrevistados apresentaram ressalvas no que tange à flexibilidade, ao afirmarem que, embora seja importante a flexibilidade na startup em que estão inseridos, no tocante aos aspectos supramencionados, em alguns casos isso não possui compatibilidade com o volume de trabalho e com a carga horária destinada ao mesmo, conforme relatam E2 e E3:

É bem flexível comparado com qualquer outro tipo de emprego, a atividade em si [...] eu acredito que todo trabalho tem que ser flexível com relação a atividade sabe? Acho que ninguém tem que tá preso no seu quadradinho. Só que tem uma linha muito tênue que até que ponto essa flexibilidade pode se tornar abusiva com a pessoa entendeu? Tipo, com um estagiário, que a gente sabe que é uma realidade de muitas empresas (E2).

“Não sei se a palavra certa seria baldeado, né? Mas essa questão de flexibilidade é muito baldeado. Às vezes você tem a flexibilidade muito grande, e às vezes você tem uma demanda de carga de trabalho que não cabe no horário" (E3). Tal cenário de sobrecarga foi um pouco mais aprofundado por E5, ao relatar que algumas vezes viveu um relacionamento abusivo com a organização:

Eu mesma vivi um pouco de um relacionamento abusivo ali, porque eu me permiti ser menos eu em alguns momentos, no sentido de não me cuidar, de deixar de fazer coisas, porque eu priorizei tá ali, eu tinha que dar aquele resultado e acho que isso é muito predatório pessoalmente assim... Então o que eu acho ruim de startup é que você entra nessa magia do unicórnio e acredita que aquilo ali é quem você é (E5).

A narrativa acima aponta para um estranhamento do sujeito para com ele mesmo, principalmente ao declarar que se permitiu "ser menos" em prol de seus melhores resultados para a organização, fato que pode ser caracterizado como favorável à alienação, prejudicando a atribuição de sentido ao labor por parte do sujeito, além de conduzi-lo ao sofrimento. Quando o trabalhador não reflete sobre suas atividades laborais, ele é forçado a alienar-se de todo o processo que envolve suas funções, permanecendo em um 
tempo e espaço sem sentido por longos períodos (FIGUEIREDO; ALEVATO, 2013).

Com isso, as diferentes formas que os sujeitos lidam com a flexibilidade podem acarretar danos à subjetividade e à vivência laboral, em função da produtividade, fato que, segundo Dejours (2013), pode ser caracterizado como violência no trabalho, a qual implica o agravamento das diversas patologias, como mentais, de sobrecarga e do assédio.

Além disso, cabe destacar nas narrativas a emergência da possibilidade de trabalho na modalidade home office e a liberdade que algumas startups proporcionam em relação à vestimenta dos colaboradores, fatores que as caracterizam como empresas inovadoras em suas práticas internas.

No entanto, algumas falas, como as de E4 e E5, evidenciam que tal liberdade é variável de acordo com cada setor da organização: "Alguns setores trabalham mais home office, às vezes a pessoa tá doente ou vai ter que visitar o cliente ou teve algum problema que eles pedem pra trabalhar de home office e eles trabalham. O negócio é atender a demanda, é muito isso" (E4); "É um sinal de muita liberdade. Eu tô de chinela hoje. Obviamente você pode ser julgado internamente pela forma que você se veste, isso pode definir para alguém o seu resultado, mas no final das contas, a liberdade existe e você pode usá-la. O quanto isso te afeta ou não, dependendo da sua área... isso não vai definir o seu trabalho, mas obviamente isso vai depender de quem vai tá te avaliando" (E5).

Cabe destacar que, embora as narrativas transmitam uma concepção de flexibilidade bastante intrínseca à liberdade, a fala de E5 descreve uma pseudo-liberdade, ao apresentar condições e consequências à sua existência. Logo, essa falsa impressão de flexibilidade pode ser um caminho condutor do sujeito ao sofrimento, além de ser um processo ilusório que tende a beneficiar as empresas, pois, para Antunes (2009), a flexibilização pode ser vista pelas empresas como uma forma de viabilizar sua liberdade de tomar decisões, mas também pode levar a uma precarização do trabalho.

\subsection{Mudanças}

Quatro dos entrevistados afirmaram que as startups são ambientes permeados por mudanças, principalmente objetivando 
melhorias, como relatam E3 e E4. Contudo, E4 afirma que tal característica pode ser um ponto negativo ao gerar incertezas e, em alguns casos, facilitar a recorrência de erros: "Apesar de que assim, tipo mudava muito rápido as coisas, né? Toda semana tinha mudança, uma semana tava fazendo uma coisa e depois tava fazendo outra. [...] Geralmente essas mudanças vinham para a melhoria né? Algumas coisas até hoje não sei como é que tá, mas acredito que já deve tá tendo uma melhoria, né?" (E3); "As coisas mudam muito rápido. Viu que tem um problema, então eles buscam sempre tá mudando, apesar de que às vezes insistem nos erros, mas as coisas mudam muito rápido. Um mês na empresa parece um semestre, sabe? as coisas são bem intensas [...] Então eu acho que a incerteza é legal, mas ao mesmo tempo é um dos principais pontos negativos" (E4).

Nota-se, a partir da narrativa de E4, um conflito diante de uma das principais características do contexto das startups: a incerteza. Apesar de reproduzir discursivamente que a incerteza é legal, o entrevistado a aponta como o ponto negativo mais forte, o que caracteriza um confronto intrassubjetivo entre o processo de construção da identidade do indivíduo e sua busca para se reconhecer também na identidade da organização.

Tal cenário caracteriza-se como favorável à patologia social de servidão voluntária que, segundo Mendes (2007), faz parte de um conjunto de armadilhas que a organização do trabalho estimula, as quais são difíceis de serem combatidas ao serem banalizadas ou ocultadas. Com isso, a subjetividade do trabalhador é contaminada, levando-os ao sofrimento e, gradativamente, ao adoecimento.

Nesse contexto, embora as mudanças sejam vistas como estímulos para melhorias, algumas vezes também geram retrabalhos, como relatado por E1 e E2. Salienta-se que, na fala de E1 é possível perceber uma possível porta para o sofrimento, quando o sujeito narra que seu trabalho nunca vai valer a pena, apresentando uma frustração por fazer algo que não será útil, devido as constantes mudanças: “Todo dia surgem coisas diferentes e eu fiquei "nossa que saco, meu trabalho nunca vai valer a pena, eu tô dando tudo de mim e não tô chegando em canto nenhum", mas tá bom, eu aceitei as mudanças, não gosto de mudanças, mas eu tive que aceitar [...] afeta no meu trabalho também, porque eu tive meio que retrabalho, né?" (E1). 
Tem muita mudança constante, tipo assim é muita mudança, muita mudança. Tá fazendo uma coisa de um processo, do nada muda, e do nada muda, e do nada muda. E ao mesmo tempo que é bom, por que pô, tu tem que ficar se adaptando e tal, você tá aprendendo coisa diferente, ao mesmo tempo é muito complicado, tu conseguir definir uma organização de atividades, por que tudo é muito volátil, entendeu? (E2).

De acordo com Ries (2012), as incertezas fazem parte da definição de startups e afirma a importância de gerenciá-las, porém, segue dizendo que as ferramentas de gestão utilizadas, predominantemente em empresas tradicionais, não foram criadas para esses ambientes de constantes mudanças. Tal fato ressalta a característica inovativa de muitas startups ao desenvolverem suas próprias ferramentas de gestão para dar conta das imprecisões, mas as narrativas reforçam a importância do gerenciamento das mudanças para o melhor desenvolvimento da organização do trabalho.

\subsection{Organização do trabalho}

A organização do trabalho foi a dimensão da PDT mais recorrente entre as narrativas, sendo identificado nas falas de todos os entrevistados. Eles relataram como são organizadas suas atividades no dia a dia e quatro deles afirmaram que enfrentam problemas causados pela falta de organização nos processos de trabalho, como retrabalhos, esforços desnecessários e falta de direcionamento, como narram E1 e E2: “Eu já tinha cadastrado tudo no sistema desde janeiro até setembro, não resolveu nada... joga no lixo tudo do sistema e começa Excel. Aí a gente cadastrou tudo no Excel... eu senti que eu tava fazendo um retrabalho e eu falei, só que quando você fala retrabalho ninguém gosta né?" (E1); "Só que aí, gerou retrabalho pra mim, entendeu? Mas aí, eu sei que tipo, é problema de uma raiz, tipo assim, desde a implementação do sistema. Da pessoa, da educação que a pessoa que tem a receber aquele treinamento, da prática que ela teve" (E2).

Ademais, E4 destaca que, por seu cargo ser novo, não existem atividades definidas e se sente perdida, tendo que muitas vezes buscar outras atividades para realizar. Embora a quase inexistên- 
cia de prescrições possa viabilizar a utilização da inteligência e inventividade do sujeito, tal cenário impede o desenvolvimento do trabalho vivo que, para Dejours (2013), é o que o indivíduo acrescenta às prescrições para alcançar os objetivos que estão sob sua responsabilidade.

“Mas aí até então eles não têm uma vaga definida, então de vez enquanto eu fico meio que... sem saber o que fazer, aí eu vou atrás de fazer entendeu? Fica meio perdido, porque realmente é nova essa vaga" (E4). Com isso, é possível perceber que a falta de prescrições, por vezes, pode ser vista como uma falha na organização do trabalho, tornando-se porta para o sofrimento laboral.

Um ponto interessante a ressaltar emergiu na narrativa de E5, ao afirmar que as startups se assemelham às empresas tradicionais em relação aos processos, pois também possuem muitas atividades burocráticas e nem sempre tecnológicas, como muitas empresas menos inovadoras: "Mas assim, tem ponto, tem folha, tem planilha pra caramba, entendeu? Tem que cumprir processo, procedimento, é desligamento, tem sindicato, então assim coisas que vem da tradicional, não tem jeito" (E5).

Identifica-se que a burocracia é diretamente relacionada às formas mais tradicionais de trabalho, como se não fosse condizente com a contemporaneidade. Tal fato reforça o pensamento de Gaulejac (2007) de que a burocracia é apontada como algo que empobrece o trabalho e torna os sujeitos alienados, diante das possibilidades trazidas pelas novas empresas, principalmente no tocante à autonomia e liberdade.

\subsection{Relações de trabalho}

As relações de trabalho ocuparam a segunda posição dentre as dimensões da PDT mais recorrentes nos relatos dos entrevistados, os quais puderam descrever um pouco de como são suas relações com colegas de trabalho, superiores, fornecedores e clientes da startup.

As relações com os colegas foram apresentadas de forma positiva pelos entrevistados, sendo ressaltados, em alguns casos, fortes laços de amizade e espaço para os sujeitos serem autênticos sem receios: "As minhas relações de trabalho lá na empresa foram muitos de boas, tipo assim, eu nunca tive conflito com uma pessoa 
não, e apesar de algumas pessoas lá, tiveram conflitos com outras lá, eu nunca fui de confusão não, tipo eu era bem amigável com todo mundo (E3); “O Fit Cultural lá é muito forte e aí então, tipo todo mundo age muito como amigo, então lá comum ter gente que os melhores amigos tão lá dentro, já saiu relacionamento de lá, então é tudo muito forte" (E4); "Os pontos positivos de trabalhar em uma startup são as pessoas que tão lá, porque realmente são pessoas que se propõem a ter uma visão de mundo mais livre de alguma forma [...] Então eu pude ser muito livre e ser quem eu sou, sabe?" (E5).

No entanto, alguns entrevistados trabalham sozinhos em suas funções, fato que, embora possibilite a manutenção de uma boa relação com os outros colegas, gera solidão e o desejo de terem mais pessoas para conversar sobre o trabalho que realizam: "Com colegas é boa a relação. Ainda que, por ser o único financeiro, eu não tenha que falar com nenhum, entendeu? Não tem. Sobre coisas, assim, de trabalho... Nada. Então normalmente eu fico na minha [...] eu queria até que tivesse, sabe... Gente pra falar mais sobre o assunto" (E1); "E com os times no geral eu interajo com todos, eu não tenho um time, eu sou mais só na forma de trabalho [...] Então eu acho que é isso, são as pessoas e a forma que elas se relacionam sabe... mesmo quando é pesado, a gente consegue se tornar um pro outro leve [...] mas pra mim o pior é que eu me sentia só" (E5).

É importante observar que a incidência de cargos individuais, como os exemplos supramencionados, pode manter com maior frequência os sujeitos expostos a vivências de sofrimento, pois eles são privados de uma das fontes mais relevantes de prazer aos trabalhadores: o julgamento de seus pares. Ao ser reconhecido pelos seus pares o indivíduo se sente parte da equipe, do coletivo, evitando a solidão e o impacto direto da mesma sobre a relação subjetiva do trabalho com a saúde mental (DEJOURS, 2013).

Além disso, foram mencionados momentos interativos, promovidos pela empresa, para estimular o bem-estar e as relações entre os sujeitos, conforme relatam E1 e E2: “Toda quinta-feira a gente tem um filme que passa pra inspirar nossos colaboradores, aí a gente pede pizza, vai pra sala de reunião maior [...] era um momento menos formal, que eles podiam discutir ideias inspiradoras para o futuro da startup, um momento que eles podiam ouvir mais 
os funcionários, que os funcionários tinham mais tempo pra falar com eles, ter essa interação” (E1); “Uma vez por mês eles fazem um momento pra reunir as pessoas, ai às vezes eles chamam uma pessoa pra palestrar, tipo de outra startup que fica interessante [...] tem esses ritos que a empresa faz meio que pra aproximar e pra deixar um clima mais leve" (E2).

Nesse contexto, é possível inferir que tais momentos promovidos pelas startups, ao viabilizar discussões e encorajar debates inspiradores da cooperação, se caracterizam como espaços de deliberação. Tais espaços são definidos por Dejours (2013) como âmbitos de reajustamento e transmissão das regras de trabalho coordenadas, onde podem ocorrer "interpretações coletivas" das mesmas, admitindo que debater sobre diferentes modos operatórios e suas possíveis vantagens, ou desvantagens, para a cooperação são essenciais para o trabalho coletivo.

Em relação aos cargos mais altos na hierarquia das startups, as relações descritas pelos entrevistados foram boas em sua maioria, apontando líderes acessíveis e que ouvem os trabalhadores, conforme destaca E2: “O meu supervisor da operação é uma pessoa muito tranquila, muito... ele é de boa e tal, tá lá pra ajudar, mais principalmente tá pra ouvir a gente, entendeu?" (E2).

Entretanto, relatos como de E3 e de E4 apresentam pontos de incômodo, como autoridade limitada e maior incidência de proteções para trabalhadores específicos: "É porque o chefe acatava tudo da gente, tipo, meu líder era excelente, não tinha o que reclamar dele, sendo que dele para cima as coisas não iam, entendeu?" (E3); "A minha líder fala que ela é mãe coruja, ela defende muito, tem uns que adotam. Às vezes acaba que eles superprotegem algumas pessoas, entendeu? O pessoal fala muito isso. Eu já tinha percebido, mas não era algo que me incomodava" (E4).

No tocante às relações externas, o relacionamento com os clientes, no geral, foi descrito como bom, embora muitas vezes envolva a resolução de problemas que pode, por vezes, desgastar os trabalhadores: “Em relação aos clientes, como a gente tá tratando diretamente com problemas, que a gente sente muito a indignação deles, a gente sente que eles sabem que isso ajuda entendeu?" (E2); "A minha relação com meus clientes é muito boa, mas sempre tem 
um cliente muito difícil. [...] É surreal como às vezes é desgastante só um. Tem uma minha que pede suporte todo dia, e é muito desgastante porque ela é grosseira." (E5).

No entanto, o mais preocupante dentre os relatos foi o relacionamento com fornecedores, o qual foi descrito como algo complicado e estressante: "Com os fornecedores é um pouco complicado. Hoje eu me estressei, por que o cara faz as coisas, tipo, ele é uma pessoa bem arrogante, e ele é todo... fez um monte de coisa errada" (E2); "Relacionamento com o fornecedor é uma coisa que desgasta muito, porque a gente depende de outras pessoas pra resolver o problema" (E5).

Nota-se mais uma forma de exposição dos sujeitos às vivências de sofrimento, dessa vez fora da organização interna do trabalho da startup, mas que requer estratégias por parte dos envolvidos e da própria organização, de modo a preservar tanto seus funcionários, como as relações externas que se mantêm importantes, embora desgastantes.

\subsection{Condições de trabalho}

O tema condições de trabalho envolve as percepções dos entrevistados em relação ao espaço físico do seu ambiente de trabalho, com destaque para a beleza do espaço físico, o barulho e o layout. E1 relata que a startup em que trabalha possui equipamentos de qualidade e conforto, além de todos compartilharem o mesmo salão como lócus de trabalho, o que passa para ele uma sensação de linearidade:

Eles trabalhavam no mesmo escritório, tudo integrado, deu pra perceber logo que eu ia sentar do lado do diretor, do gerente, do estagiário, então era tudo ali, todo mundo se comunicava uns com os outros, era algo bem linear, então essa foi a primeira impressão e o escritório é uma coisa que todo mundo fica impressionado, porque o escritório é muito bonito, muito aconchegante, tudo de muita qualidade, novo, tecnológico aí de cara eu já gostei (E1).

E5 também relata que seu ambiente de trabalho é agradável, com destaque para a existência de espaços alternativos de trabalho, mais descontraídos e confortáveis, mas que com o passar do tempo as 
pessoas tiveram menos liberdade para trabalhar nesse espaço, com a imposição de restrições: “Tem pufes, tem salas com ar condicionado, é muito confortável, mas ao mesmo tempo é ok... até um tempo atrás, todo mundo tinha muita liberdade de onde queria trabalhar e tudo, hoje em dia já tem umas certas restrições, entendeu? "Ah não é pra ficar trabalhando no pufe, tem que ficar mais na sua sala e departamento dependendo da área" (E5).

O barulho foi um aspecto comentado por três dos entrevistados como um incômodo ao trabalho, levando alguns sujeitos a buscar locais alternativos para escapar dos ruídos, conforme relatam E3 e E4 preferem ir trabalhar em outros locais devido o barulho: "A pessoa que trabalhava atrás de mim, falava gritando, então incomodava muito, incomodava bastante, me desconcentrava bastante, e eu gosto de fazer minhas coisas tipo concentrado, tipo às vezes eu preferia ficar lá em cima entendeu? por causa do frio, do barulho, vários aspectos" (E3); "Tipo assim, a sala tá muito barulhenta ou então eu não quero mais ver ninguém, aí eu subo, boto meu fone e ninguém mexe comigo" (E4).

Nota-se que é comum identificar startups com seu lócus de trabalho compartilhado entre diversos setores, fato que, além dos aspectos supramencionados, também pode acarretar em uma ausência de privacidade, como no caso de E1 que trabalha manuseando senhas, dados restritos, contas da empresa e não se sente confortável com os olhares: “E quanto ao financeiro, eu acho, assim, por tá lá no meio de todo mundo... É meio complicado, sabe? Você tá mexendo em banco, com todo mundo olhando. Sei lá, eu entrar com a senha do banco, e tá lá todo mundo" (E1).

E3, que trabalha com atividades comerciais, também relatou limitações, como quando precisa ensaiar discursos antes de visitar clientes e não se sente à vontade para isso diante dos outros colegas: "Então eu tinha que testar esses discursos, tipo às vezes eu não ficava tão... Como eu posso dizer... confortável, ficar confortável em ficar com outras pessoas ao meu redor... Ao meu lado, e ficar testando esse discurso, ai eu preferia ficar só, que eu conseguiria me concentrar melhor e fazer o que eu queria, entendeu?" (E3).

Dejours (2013) aponta que as discrições, principalmente envolvendo tarefas que exijam a segurança de informações permeadas 
por riscos, condenam a inteligência do sujeito, o qual passa por diversas situações que requerem controle e vigilância em seus modos operatórios.

\subsection{Reconhecimento}

De acordo com Merlo (2002), o reconhecimento não se resume somente a recompensar o trabalhador pelo seu esforço e colaboração, por meio de bonificações ou premiações, mas consiste em considerar o conjunto de atitudes do trabalhador para a execução do trabalho.

As narrativas dos entrevistados deixaram clara a pouca incidência do reconhecimento em seus respectivos contextos laborais, o que contribui para a maior exposição dos sujeitos ao sofrimento, já que uma importante fonte de prazer tem sido negligenciada aos mesmos, conforme relatam E1 e E5: "Falta eles acreditarem mais em mim, porque eles que tomam as decisões, mas eles não ligam muito pro financeiro. Deixam o financeiro assim de lado. Querem botar para outra empresa fazer, porque eles não querem saber. Mas eu seria hoje a melhor opção para isso" (E1).

E quando eu falo valorização não é só o tapinha nas costas, "parabéns", "deu o gás e tal", mas tipo, bateu meta... vamos almoçar junto? Vamos conversar? Entendeu? É cuidado, entendeu? Tipo assim eu sou teu líder, ah tu fez tal coisa, vem cá, manda um recado, fala com a pessoa... Eu não sei nem definir como é, porque eu não sei nem mais o que é isso, pra ser bem sincera, mas assim é uma valorização real, não é aquela coisa que você ganha moto depois de fazer um ano e tal, que é muito massa também adoro, mas isso não define, isso é tipo funcional [...] é cuidado no dia a dia, são pequenos detalhes assim da rotina, é olhar pra ti e dizer nossa como tu é criativa, é o dia a dia (E5).

Entretanto, uma constatação interessante entre as narrativas foi a de que a recompensa simbólica, de fato, tem grande valor para os trabalhadores, reforçando que o reconhecimento vai muito além de retornos materiais. No caso de E1, por exemplo, ações simbólicas da startup para seus funcionários estimulam a autoestima e geram um sentimento de pertença familiar em relação à organização: "Ah, de promover festa, sabe? Festa de halloween, festa de Natal, festa de... 
Sei lá. Festa de aniversariante do mês. Isso é muito bom para os funcionários, sabe. Faz com que eles sintam mais familiarizados. Faço parte da família. É... Mexe até com a autoestima dos funcionários. Realmente eu gosto disso. Eu acho isso positivo" (E1).

Conforme apontam Freitas e Facas (2013), o valor simbólico do reconhecimento é oriundo do sentido que o sujeito atribui à sua vivência laboral, aproximando-o de suas expectativas profissionais e colaborando para a transformação do sofrimento em prazer. Logo, é importante uma análise aprofundada, por parte das startups, acerca dos motivos que podem estar distanciando o reconhecimento dos sujeitos, pois, segundo Aguiar e Batista-dos-Santos (2017), quando a dinâmica do reconhecimento não funciona, a transformação do sofrimento em prazer também não ocorre, destruindo o sentido subjetivo do trabalho e fomentando a emergência de patologias.

\subsection{Estratégias de defesa}

A utilização de estratégias de defesa pelos trabalhadores para lidar com o sofrimento foram bastante identificadas durante as entrevistas, principalmente para fugir do cansaço mental e da ansiedade. No caso de E3, por exemplo, era importante realizar pausas em suas atividades, de modo a mudar o ambiente, ouvir músicas ou conversar com colegas de trabalho para cuidar do seu psicológico e seguir com suas atividades de modo mais eficaz.

Quando eu ficava assim bem cansado mesmo mentalmente, sei lá, ia lá pra fora, pra varanda, lá em cima, tomava café, batia um papo com as pessoas, ou então ficava escutando uma música, dava uma pausa mesmo assim, entendeu? [...] Tipo, isso me ajudava, melhorava minhas prospecções. [...] Eu gosto de cuidar muito da minha mente, entendeu? Então, tipo, quando eu sentia que tava meio sei lá, tão ansioso, alguma coisa assim, afetando meu psicológico, meio que eu já buscava coisas pra me prevenir, sabe? [...] tipo eu conversava mesmo com as pessoas, adoro desabafar com as pessoas. E lá na empresa tinha um grupo, que a gente desabafava assim, para mim meio que extravasava mesmo assim as coisas (E3). 
Com isso, nota-se que existem relações de confiança entre os trabalhadores, de modo a cooperarem uns com os outros, por meio da escuta, para favorecer o confronto com o real do trabalho. Inclusive, para Dejours e Gernet (2012), não existe a cooperação sem a estruturação de relações de confiança entre os sujeitos (DEJOURS; GERNET, 2012).

Ainda na seara psicológica, alguns entrevistados mencionaram a psicoterapia como uma boa alternativa para lidar com a ansiedade do cotidiano laboral, como é o caso de E4, em que sua startup incentiva tal prática e busca sempre abordagens sobre saúde mental.

Eu tava tendo acompanhamento psicológico, né porque eu sou uma pessoa ansiosa e na época eu tive bons resultados, na verdade muito bons, que trouxeram muitos clientes, por que eu fazia prospecção né? [...] Porque o pessoal é novo, então fala muito sobre ansiedade, a importância de ir pro psicólogo essas coisas, então lá era muito comum, até porque tem gente que já tinha ido no psiquiatra, por conta da vida mesmo, antes mesmo da empresa (E4).

Conforme Silva e Piolli (2017), as defesas contra o sofrimento são essenciais para evitar o adoecimento, revelando que, em meio às exigências do real do trabalho, os trabalhadores conseguem buscar tais estratégias em prol do equilíbrio e da saúde da mente.

\section{Considerações Finais}

Esta pesquisa buscou compreender a relação prazer-sofrimento, no contexto das startups, à luz da Psicodinâmica do Trabalho. Inicialmente foi possível caracterizar o contexto de trabalho das startups por meio, principalmente, dos temas flexibilização e mudanças. A flexibilização foi vista pelos trabalhadores de forma positiva, no tocante à liberdade de formas de trabalhar, como por home office, e de vestir, com dress code amplo e casual. No entanto, aspectos negativos foram destacados, como o volume de trabalho ser, por vezes, maior do que a carga horária consegue suprir, bem como o fato de a liberdade ser diferente entre setores.

As constantes mudanças, em geral, foram vistas como um aspecto negativo pelos entrevistados, pois, além de gerar incertezas, 
retrabalhos e contribuir para a recorrência de erros, também provocam a frustração dos sujeitos que não veem seu trabalho sendo, realmente, efetivo, mas sim rapidamente substituído. Aprofundando as análises para identificar com maior clareza os fatores geradores de prazer e/ou sofrimento, a caracterização do contexto de trabalho das startups contou com o auxílio das lentes da PDT, possibilitando a análise de aspectos como a organização do trabalho, as relações de trabalho, as condições de trabalho, o reconhecimento e as estratégias de defesa.

A organização do trabalho foi descrita pela maior parte dos entrevistados como composta por processos de trabalho ainda desorganizados, propícios a retrabalhos e esforços desnecessários, além de uma falta de direcionamento. Tal fato decorre, principalmente, da ausência de prescrições por parte das startups que, embora por um lado denote flexibilidade, por outro dificulta a ocorrência do trabalho vivo, sendo uma porta mais representativa para o sofrimento do que para o prazer.

As relações de trabalho foram descritas, em geral, de forma positiva, com exceção das relações externas, com clientes e, principalmente, com fornecedores, apresentadas em alguns momentos como desgastantes, tanto por lidarem com os problemas dos clientes, como por dependerem dos fornecedores para solucionar alguns problemas. Com isso, nota-se que, internamente, as relações com os demais colegas de trabalho contribuem para vivências de prazer nas startups, mas as relações externas podem, por vezes, ser potenciais fontes de sofrimento aos envolvidos.

As condições de trabalho foram identificadas como propícias ao prazer quando relatadas de forma positiva pelos entrevistados no que tange à estrutura do ambiente de trabalho, o qual foi descrito como confortável, com recursos materiais de qualidade e adequados à execução das atividades. Contudo, alguns aspectos negativos foram pontuados, como o layout desfavorável à privacidade de determinados setores, bem como o barulho.

Um importante resultado do estudo foi em relação ao reconhecimento, não só a sua evidente ausência nas startups analisadas, mas também a forma de retribuição esperada pelos sujeitos, que não era material, mas sim simbólica. Ao negligenciar o reconhecimento 
as organizações tornam seu contexto propício ao sofrimento e, até mesmo, ao desenvolvimento de patologias.

Outro achado da pesquisa se deu em relação às estratégias de defesa utilizadas pelos sujeitos, tanto para evitar as possibilidades de sofrimento supramencionadas, como para lidar com o sofrimento já instalado. Os entrevistados destacaram, além das relações de confiança e cooperação, também a importância do acompanhamento médico e psicológico para a manutenção da saúde mental, fato estimulado pelas próprias startups.

Perante os resultados obtidos nessa pesquisa, conclui-se que as vivências de prazer são mais representativas do que as vivências de sofrimento nas startups, tendo em vista que, embora os sujeitos sejam expostos a situações que viabilizam um movimento pendular entre ambas as vivências, o sofrimento não foi identificado de forma objetiva nas falas, mas sim diversas portas que podem promover a sua emergência, bem como limitações que dificultam a existência de prazer em determinados aspectos da organização do trabalho.

Em termos de limitações do estudo, pontua-se que não foi possível realizar entrevistas com gestores, fato que poderia aprofundar ainda mais o estudo, além da quase inexistência de pesquisas que relacionem startups e PDT, para fins de diálogos teóricos. Nesse contexto, compreende-se também que a Psicodinâmica do Trabalho se apresentou como uma lente teórica adequada para a investigação do objeto de estudo, visto que permitiu a identificação e o aprofundamento dos temas tratados, de modo a estimular outras pesquisas. Estudos futuros podem examinar o objeto de estudo em questão de forma mais ampla, junto a um maior número de startups e de entrevistados, incluindo maiores níveis hierárquicos, bem como podem dedicar-se à investigação das temáticas que apareceram como portas para desencadear o sofrimento, para que assim seja possível, de fato, identificar possíveis processos de adoecimento dos trabalhadores.

Diante disso, a pesquisa apresenta como contribuição acadêmica a análise de uma temática ainda incipiente, que é o contexto de trabalho das startups, socializando os discursos que as permeiam, de modo a viabilizar diálogos teóricos com estudos futuros. Tal contribuição se torna ainda mais relevante sob a ótica da psicodinâmica do trabalho, formando uma combinação de construtos quase 
inexistente e bastante pertinente diante das constantes mudanças mercadológicas às quais as startups são expostas. Assim, a pesquisa se torna também um subsídio prático para a gestão das startups compreenderem melhor seu contexto laboral e traçar estratégias adequadas à melhoria da relação homem-trabalho.

\section{REFERÊNCIAS}

ASSOCIAÇÃO BRASILEIRA DE STARTUPS. Site. Disponível em: https://abstartups.com. br/crescimento-das-startups/. Acesso em: 14 mar. 2020.

AGGARWAL, V.; WU, A. Inter-Organizational Collaboration and Start-Up Innovation. In: MATUSIK, S. F; REUER, J. J. (eds.). The Oxford Handbook of Entrepreneurship and Collaboration. Oxford, UK: Oxford University Press. Forthcoming, 2018.

AGUIAR, R. G.; BATISTA-DOS-SANTOS, A. C. Conflitos nas relações sociais de trabalho no contexto da nova gestão pública à luz da psicodinâmica do trabalho. 2017. 129 f. Dissertação (Mestrado Acadêmico em Administração) - Centro de Estudos Sociais Aplicados, Universidade Estadual do Ceará, Fortaleza, 2017.

ANCHIETA, V. C. C.; GALINKIN, A. L.; MENDES, A. M. B.; NEIVA, E. R. Trabalho e riscos de adoecimento: um estudo entre policiais civis. Psicologia: Teoria e Pesquisa. Brasília, v. 27, n. 2, p. 199-208, abr./jun. 2011.

ANDRADE, M. M. Introdução à metodologia do trabalho científico: elaboração de trabalhos na graduação. 6. ed. São Paulo: Atlas, 2003.

ANTUNES, R. Século XXI: nova era da precarização estrutural do trabalho? In: ANTUNES, R.; BRAGA, R. (Orgs.). Infoproletários: degradação real do trabalho virtual. São Paulo: Boitempo, p. 231-238, 2009.

BARDIN, L. Análise de Conteúdo. São Paulo: Ed. 70, 2011.

BENSON, D.; ZIEDONIS, R. H. Corporate venture capital as a window on new technologies: Implications for the performance of corporate investors when acquiring startups. Organization Science, v. 20, n. 2, p. 329-351, 2009.

CARVALHO, G. M.; MORAES, R. D. Sobrecarga de trabalho e adoecimento no Polo Industrial de Manaus. Psicologia em Revista, Belo Horizonte, v. 17, n. 3, p. 465-482, dez. 2011.

DEJOURS, C. A loucura do trabalho - Estudo de psicopatologia do trabalho. SP, Ed. Cortez, 1992.

DEJOURS, C. Travail vivant, t. 02: Travail et émancipation. Paris: Payot, 2013.

DEJOURS, C.; ABDOUCHELI, E.; JAYET, C. Psicodinâmica do trabalho: contribuições da escola dejouriana à análise da relação prazer, sofrimento e trabalho. São Paulo: Atlas, 1994.

DEJOURS, C.; GERNET, I. Travail, subjectivité et confiance. Nouvelle Revue De Psychosociologie, p. 75-91, 2012. 
DiÁNEZ-GONZÁLEZ, Juan Pablo; CAMELO-ORDAZ, Carmen. How management team composition affects academic spin-offs' entrepreneurial orientation: the mediating role of conflict. The Journal of Technology Transfer, v. 41, n. 3, p. 530-557, 2016.

FIGUEIREDO, J. M.; ALEVATO, H. M. R. A visão de prazer e sofrimento da do trabalho ante a precarização e a intensificação do psicodinâmica trabalho: breve reflexão. In: Encontro Nacional de Engenharia de Produção, 33, 2013, Salvador. Anais... Salvador: Associação Brasileira de Engenharia de Produção, 2013.

FONTANELLA, B. J. B.; LUCHESI, B. M.; SAIDEL, M. G. B.; RICAS, J.; TURATO, E. R.; MELO, D. G. Amostragem em pesquisas qualitativas: proposta de procedimentos para constatar saturação teórica. Cadernos de Saúde Pública, v. 27, p. 388-394, 2011.

FREITAS, L. G.; FACAS, E. P. Vivências de prazer-sofrimento no contexto de trabalho dos professores. Estud. pesqui. psicol., Rio de Janeiro, v. 13, n. 1, p. 7-26, abr. 2013.

GASKELL, George; BAUER, Martin W. Pesquisa qualitativa com texto, imagem e som: um manual prático. Petrópolis, RJ: Vozes, v. 74, 2002.

GAULEJAC, V. Gestão como doença social: ideologia, poder gerencialista e fragmentação social. São Paulo: Ideia e Letras, 2007.

GERNET, I. Actualités de la recherche en psychodynamique du travail. Ann Med Psychol, Paris, p. $1-4,2016$.

GIONGO, C. R., MONTEIRO, J. K., SOBROSA, G. M. R. Psicodinâmica do Trabalho no Brasil: Revisão Sistemática da Literatura. Trends in Psychology / Temas em Psicologia, v. 23, n. 4, p. 803-814, 2015.

GITAHY, Y. Portal Revista Exame, O que é uma Startup?, 2016. Disponível em: $<$ https:// exame.com/pme/o-que-e-uma-startup/>. Acesso em: 13 mar. 2020.

GROHMANN, R. Faça o que você ama?: o consumo do trabalho adjetivado e a startup 99Jobs. Animus, Santa Maria, v. 17, n. 33, p. 212-226, 2018. Disponível em: <http://dx.doi. org/10.5902/2175497720817>. Acesso em: 20 nov. 2020.

HUYNH, T.; PATTON, D.; ARIAS-ARANDA, D.; MOLINA-FERNÁNDEZ, L. M. University spin-off's performance: Capabilities and networks of founding teams at creation phase. Journal of Business Research, v. 78, p. 10-22, 2017.

ISIDRO-FILHO, A.; GUIMARÃES, T. A. Conhecimento, aprendizagem e inovação: uma proposta de articulação conceitual. Revista de Administração e Inovação. São Paulo, v. 7, n. 2, p. 127-149, 2010.

KOHLER, T. Corporate accelerators: Building bridges between corporations and startups. Business Horizons. v. 59, n. 3, p. 347-357, 2016.

MACHADO, P.; BLATTMANN, U.; TEIXEIRA, C. Mapeamento da produção científica sobre startups em bases de dados internacionais: Relação entre informação, tecnologia e inovação. In: Encontro Nacional de Pesquisa em Ciência da Informação, 19, 2018, Londrina. Anais... Londrina: Universidade Estadual de Londrina, p. 2925-2931, 2018. 
MARCELINO, P. As Palavras e as Coisas: uma nota sobre a terminologia dos estudos contemporâneos de trabalho. Mediações - Revista de Ciências Sociais, v. 16, n. 1, p. 55-70, 2011.

MCGRATH, Helen; MEDLIN, Christopher J.; O'TOOLE, Thomas. A process-based model of network capability development by a start-up firm. Industrial Marketing Management, v. 80, p. 214-227, 2019.

MENDES, A. M. Psicodinâmica do Trabalho - Teoria, Método e Pesquisas. 1 ed. São Paulo: Casa do Psicólogo, 2007.

MENDES, A. M.; FERREIRA, M. C. Contexto de Trabalho. In: SIQUEIRA, M. M. (Org.). Medidas do Comportamento Organizacional: Ferramentas de Diagnóstico e Gestão. Porto Alegre, RS: Artmed, p. 111-123, 2008.

MERLO, A. R. C. Psicodinâmica do Trabalho. In: JACQUES, M. G.; CODO, W. (Orgs.). Saúde mental \& trabalho: leituras. Petrópolis: Vozes, p. 130-142, 2002.

MERLO, A. R. C.; MENDES, A. M. B. Perspectivas do uso da psicodinâmica do trabalho no Brasil: teoria, pesquisa e ação. Cad. psicol. soc. trab., São Paulo, v. 12, n. 2, p. 141-156, dez. 2009. Disponível em: $<$ http://pepsic.bvsalud.org/scielo.php?script=sci arttext\&pid=S1516-37172009000200002\&lng=pt\&nrm=iso >. Acesso em: 20 nov. 2020.

MINAYO, M. C. S. O desafio do conhecimento: pesquisa qualitativa em saúde. 8a. ed. São Paulo: Hucitec/ Rio de Janeiro: Abrasco: [s.n.], 2004.

MINAYO, M. C. Amostragem e saturação em pesquisa qualitativa: consensos e controvérsias. Revista Pesquisa Qualitativa, v. 5, n. 7, p. 1-12, 2017.

MINAYO, M. C. S.; DESLANDES, S. F.; NETO, O. C.; GOMES, R. Pesquisa Social: Teoria, Método e Criatividade. 22 ed. Petrópolis: Editora Vozes, 2003.

MIRANDA, J. Q.; SANTOS JÚNIOR, C. D.; DIAS, A. T. A influência das variáveis ambientais e organizacionais no desempenho de startups. Revista de Empreendedorismo e Gestão de Pequenas Empresas, v. 5, n.1, p. 28-65, 2016.

NOGUEIRA, J. H. V.; FREITAS, L. G. Psicodinâmica do estresse: estudo com trabalhadores de pesquisa, desenvolvimento e inovação. Rev. psicol. organ. trab, 2015.

OLIVEIRA, H. N. “Eu tenho um ambiente maravilhoso, mas eu tenho um ambiente enorme de incertezas": prazer e sofrimento no trabalho no contexto das startups. 2017. 91 f. Dissertação (Mestrado em Psicologia). Programa de Pós-graduação em Psicologia, Universidade Federal do Maranhão, São Luís, 2017.

PIRES, A. P. Amostragem e pesquisa qualitativa: Ensaio teórico e metodológico. In: POUPART, J. et al. A pesquisa qualitativa: enfoques epistemológicos e metodológicos. Rio de Janeiro: Vozes, 2008.

RIES, E. A startup enxuta: como os empreendedores atuais utilizam a inovação contínua para criar empresas extremamente bem-sucedidas. São Paulo: Lua de Papel, 2012.

SILVA, A. V.; PIOLLI, E. A centralidade do trabalho na psicodinâmica de Christophe Dejours, o campo educacional e o trabalho docente: aproximações possíveis. Devir Educação, v. 1, p. 50, 2017. 
VAN GELDEREN, M.; THURIK, R.; BOSMA, N. Success and risk factors in the pre-startup phase. Small business economics, v. 24, n. 4, p. 365-380, 2005.

VIEIRA, A. M.; RIVERA, D. P. B. A Hermenêutica no Campo Organizacional: duas possibilidades interpretativistas de pesquisa. Revista Brasileira de Gestão de Negócios, v. 14, n. 44, p. 261-273, 2012.

WALLIN, A., STILL, K.; HENTTONEN, K. Entrepreneurial growth ambitions: The case of Finnish technology startups. Tech-nology Innovation Management Review, v. 6, n. 10, p. 5-16, 2016.

Recebido em: 15-2-2021

Aprovado em: 7-12-2021

Avaliado pelo sistema double blind review.

Disponível em http://mjs.metodista.br/index.php/roc 